\title{
Trials and Tribulations: Psychopathic Traits, Emotion, and Decision-Making in an Ambiguous Case of Sexual Assault
}

\author{
Kristine A. Peace*, Raeanne L. Valois \\ Department of Psychology, City Centre Campus, Grant MacEwan University, Edmonton, Canada \\ Email: PeaceK@macewan.ca
}

Received 7 June 2014; revised 5 July 2014; accepted 1 August 2014

Copyright (C) 2014 by authors and Scientific Research Publishing Inc. This work is licensed under the Creative Commons Attribution International License (CC BY). http://creativecommons.org/licenses/by/4.0/

(c) (i) Open Access

\begin{abstract}
Judgments of criminal culpability often are influenced by factors unrelated to case content, such as the emotionality of the victim and the personality of the judge. In the current study, we investigated the relationship between psychopathic traits (high/low) and information processing modes (experiential vs. rational) in a group of mock jurors $(N=383)$ asked to judge a "he said, she said" ambiguous case of sexual assault that varied according to both victim and defendant emotionality (high/low). The results demonstrated that victim and defendant emotionality was critical in determining case outcomes, which interacted with the processing style that participants utilized more. Specifically, experiential processors were more punitive towards the defendant when the defendant displayed low levels of emotion relative to high emotionality, whereas rational processors were slightly more punitive when high levels of emotion were being displayed. Psychopathic traits had no influence on ratings of veracity/credibility of the victim and defendant, or on overall guilt determinations and severity of sentencing. However, participants high in psychopathic traits believed that the alleged victim was making a false allegation more often when she was less emotional, and they were less punitive towards the false allegation than individuals low in psychopathic traits. These findings have important implications concerning how cases of sexual assault are interpreted in court, and extra-legal factors that may alter case outcomes.
\end{abstract}

\section{Keywords}

Sexual Assault, Emotionality, Psychopathic Traits, Rational Versus Experiential Processing, Veracity, Sentencing Outcomes

\footnotetext{
*Corresponding author.
} 


\section{Introduction}

Extant research has established that jurors are often influenced by not only the facts in a case, but extralegal factors (e.g., attractiveness, gender) that have no bearing on the case itself (e.g., Mazzella \& Feingold, 1994; Peace \& Forrester, 2012). One such factor under investigation in the present study is the emotionality of a claim and whether this influences witness credibility. Past research has suggested that expressed emotion and emotional displays are highly relevant to consider in judicial decision-making (e.g., Block, Greenberg, \& Goodman, 2009; Kaufmann, Drevland, Wessel, Overskeid, \& Magnussen, 2003; Wessel, Drevland, Eilertsen, \& Magnussen, 2006). Given this relationship, consideration of juror factors that may affect the interpretation of emotionality, such as the manner in which persons process information (i.e., rational versus emotional; Epstein, 2003) or the degree to which they have emotional processing deficiencies (i.e., psychopathy; Dutton, 2012) also is critical. Research has established that information processing is highly relevant to judicial biases (e.g., Gunnell \& Ceci, 2010). Further, while the construct of psychopathy is highly related to courtroom decisions concerning defendant guilt and the death penalty (e.g., Blais \& Forth, 2014; Edens, Petrila, \& Buffington-Vollum, 2001), little is known about how psychopathic traits in jurors influence their processing of information. Given that $1 \%-3 \%$ of the general population may contain high levels of psychopathic traits (Hare, 1996), determining the influence of this construct on courtroom decisions is relevant and warranted. While the task of jury decision-making is complex enough (Holstein, 1985), evaluation of extra-judicial factors that may unduly influence jurors is critical to better understand and prevent biases within the criminal justice system.

\subsection{Information Processing Pathways}

Given that juror characteristics can influence decision-making, the way in which jurors process information may be particularly relevant to judicial outcomes. Research in cognitive experiential self theory (CEST) has demonstrated that individuals employ two different pathways for processing information: experiential processing versus rational processing (Epstein, 2003). The first pathway is highly affect-oriented, involves rapid processing, is preconscious, and based on past experiences (experiential or E-processors); whereas the second pathway is more analytic, logical, reason-oriented, occurs consciously, and is effortful (rational or R-processors; Epstein, 2003). Research also has evaluated this information processing theory in relation to jury decision-making processes (e.g., Gunnell \& Ceci, 2010). In general, it appears as though E-processors are more susceptible to extralegal influences, such as attractiveness or gender (e.g., Lieberman, 2002), and may rely more on intuitive rather than evidentiary-based judgments (e.g., Krauss, Lieberman, \& Olson, 2004; Lieberman, Krauss, Kyger, \& Lehoux, 2007). For example, Gunnell and Ceci (2010) presented mock jurors with an aggravated assault case containing ambiguous evidence, as well as extralegal information such as "the defendant volunteers at a soup kitchen in his spare time", and "the defendant has a drug addiction for which he does not seek treatment" (p. 860). Their hypothesis that E-processors would be more likely influenced by extralegal factors due to reliance on intuition and emotion was supported, and extraneous information was more heavily considered in determining verdicts. As such, the processing style utilized by a juror is an important factor to consider within the legal system, especially in cases such as sexual assault that are known to be highly emotionally inflammatory and contain many implicit stereotypes about victim and defendant behaviour (e.g., Ask \& Landström, 2010; Du Mont, Miller, \& Myhr, 2003; Klippenstine \& Schuller, 2012).

\subsection{Psychopathic Traits}

To date, research involving psychopathy within the judicial system usually involves courtroom contexts where the diagnostic label of "psychopath" has been considered an aggravating factor in case outcomes and is known to heavily influence juror sentencing, verdict outcomes, and death penalty determinations (e.g., Blais \& Forth, 2014; Edens, Colwell, Desforges, \& Fernandez, 2005; Murrie, Boccaccini, \& McCoy, 2007). However, little research has evaluated psychopathic traits in juror populations. Some of the core features of the psychopathic personality include callousness, a lack of empathy, and deficits in emotional processing, which can exist in both criminal and non-criminal populations (e.g., Benning, Patrick, Hicks, Blonigen, \& Krueger, 2003). These characteristics have particular consequences for decisions involving morality and emotional empathy, such as those commonly confronted by jurors. Research has demonstrated that when empathy is induced in non-psychopathic individuals, the feeling of empathy is associated with greater resource allocation (Batson, Klein, Highberger, \& 
Shaw, 1995), situational attributions of defendant responsibility, and more lenient sentencing outcomes (Johnson et al., 2002).

On the contrary, empathy deficits would be associated with very different patterns of decision-making and case outcomes. For example, scholars have argued that psychopathic traits are associated with a greater reliance on rational processing styles when confronted with emotional material, such that they consider the facts without the empathetic response (Dutton, 2012). Given that past research has shown rational processors to be less susceptible to extralegal information in court cases (i.e., Gunnell \& Ceci, 2010), psychopathic traits may play an important role in decision-making processes about sentencing and defendant culpability within juror populations as well. The only study that has addressed psychopathy in mock jurors was conducted by Simon (1963). In this study, mental patients diagnosed as psychopaths evaluated the real life trial of Jason Lunt, and were required to make guilt determinations. Lunt was accused of having sexual intercourse with his two daughters for 14 years. He pleaded not guilty by reason of insanity. While guilt determinations made by psychopaths did not differ from other institutionalized groups (i.e., “paranoids” and “depressives”), Simon (1963) noted that psychopaths approached the case in more of a factual manner rather than being influenced by the highly emotional content of repeated sexual assault perpetrated against two young girls. This suggests that the psychopaths utilized more rational relative to experiential processing in decision-making concerning this case. In recent years, this view has transformed to a consideration of two distinct aspects of empathy: a cognitive (cold) component and an affective (hot) component (e.g., Domes, Hollerbach, Vohs, Mokros, \& Habermeyer, 2013; Dutton, 2012; Mullins-Nelson, Salekin, \& Leistico, 2006). Cognitive empathy can be described as the ability to discriminate and identify different emotional cues of other individuals, and also encompasses the ability to take another person's perspective and deduce why an individual may be expressing that particular emotion. On the other hand, affective empathy involves the emotional response that one has to another's emotional display, or the ability to experience another individual's feelings. Studies have found that psychopaths appear to show a deficit only in affective empathy (e.g., Dutton, 2012; Mullins-Nelson et al., 2006), though this has not been found consistently across all research (e.g., Domes et al., 2013). Therefore, it remains unclear how individuals high in psychopathic traits would process emotional information in court, and particularly when it is expressed by either a victim, defendant, or both.

\subsection{The Role of Emotion}

In general, empirical examination of emotionality in court has been predominantly focused on victims and their emotional displays. Not only does emotional tone and content influence memory for testimony (Block et al., 2009), but credibility of victims varies as a function of emotional expression (Kaufman et al., 2003; Wessel et al., 2006). In general, research has reported that victims who display emotions (relative to appearing non-emotional) are often seen as more credible and not responsible for being victimized (e.g., Bollingmo, Wessel, Eilertsen, \& Magnussen, 2008; Kaufmann et al., 2003). For example, Winkel and Koppelaar (1991) had participants watch either a video with an emotional (mock) rape victim, softly crying and relaying her story in a trembling voice, or a numb individual relaying her story without emotion. These researchers found that the emotional victim was seen in a more positive way; she was seen as honest, to have used caution, and was not responsible for the rape more so than the emotionally numb victim. Similarly, other studies have found support for an emotive truth bias, where emotional claims and stories are more likely to be believed and perceived as truthful relative to non-emotional claims (e.g., Peace, Porter, \& Almon, 2012; Peace \& Sinclair, 2012). Also relevant to consider is whether the emotional display of a victim is consistent with or in violation of expected norms, also called expectancy violation (i.e., a violation of a predicted pattern in behavior or emotions; Ask \& Landström, 2010; Burgoon, 1993). When an expectancy violation is made, attention is drawn away from the content of the situation and toward the individual in violation, and the possible reasons for that violation (Burgoon, 1993). Therefore, the expectancy of an emotional response (i.e., should the person be expressing emotion) may be a more important determinant of truthfulness than emotional displays on their own (e.g., Ask \& Landström, 2010; Klippenstine \& Schuller, 2012; Hackett, Day, \& Mohr, 2008).

Emotionality of defendants also has been investigated, though not to the same extent as victim emotionality. Studies evaluating defendant-displayed emotionality have found that defendants were viewed as most honest and credible, and received shorter sentences, when their emotional response was congruent with expected emotional reactions (e.g., Salekin, Ogloff, McFarland, \& Rogers, 1995). Conversely, when defendants display flat or cold affect, jurors rated these individuals as guiltier, less credible, and tend to assign harsher sentences (e.g., 
Heath, Grannemann, \& Peacock, 2004). With these results in mind, it is apparent that displayed emotional content (on behalf of both victims and defendants) is utilized in jury decisions, even though such emotionality is extraneous to the case details.

\subsection{The Current Study}

Given the connection between jury decisions and displayed emotionality, as well as the lack of empirical studies evaluating jury personality features (i.e., psychopathy and rational-experiential processing), we manipulated emotionality (high/low) in both victims and defendants to determine how this influenced jurors guilt and sentencing judgments in a "he said, she said" sexual assault case. With evidence of guilt being unclear, extralegal information such as emotionality may be a more important determinant of guilt relative to the stereotypical belief that rape allegations are unlikely to be false (Peace et al., 2012). We hypothesized the following: 1) guilt and credibility determinations will be swayed in favour of whichever person (victim or defendant) displays more emotion (i.e., if the victim is highly emotional and the defendant is not emotional, jurors will be more punitive towards the defendant and find the victim to be more credible and vice versa). When victim and defendant levels of emotionality match (both low or high), we expect that jurors will provide more mid-range ratings of guilt and credibility for defendants and victims, although still likely somewhat favouring the victim's story; 2 ) individuals high in psychopathic traits (as compared to those low in psychopathic traits) will be less likely to take emotional information into account, thereby showing little change in their sentencing, credibility, and guilt determinations across emotional conditions; and 3) R-processors will also be less likely to take emotional content into consideration, also showing consistent responses of sentencing, credibility, and guilt determinations across emotional conditions relative to primarily experiential processors, who will differ in their determinations as a function of emotional content, congruent with individuals low in psychopathic traits.

\section{Method}

\subsection{Participants}

The sample consisted of a random-selection of introductory undergraduate students $(N=383)$, with a gender breakdown of 33.9\% $(n=130)$ male and $66.1 \%(n=253)$ female and a mean age of $20.8(S D=4.25)$. Participation was voluntary and participants were able to withdraw from the study at any point without penalty. Course credit was granted in exchange for participation. This study complied with ethical guidelines, and was approved by an institutional review board.

\subsection{Measures}

Psychopathic Personality Inventory-Revised (PPI-R). The PPI-R (Lilienfeld \& Widows, 2005) is a 154-item self-report measure that taps into traits associated with the construct of psychopathy and is appropriate for use with both forensic and non-forensic samples. All items (i.e., I quickly get annoyed with people who do not give me what I want) were rated on a 4-point Likert scale (False, Mostly False, Mostly True, True). These questions assess eight dimensions of behaviour and personality, including Machiavellian egocentricity, social influence, coldheartedness, carefree nonplanfulness, fearlessness, blame externalization, rebellious nonconformity, and stress immunity. The scale produces an overall score (measuring the extent to which the participant displays psychopathic personality traits) as well as several factor scores including coldheartedness, self-centered impulsivity, and fearless dominance (Lilienfeld \& Widows, 2005). The PPI-R also contains three validity scales, which examine inconsistent, virtuous, and deviant responding. The scale has demonstrated good internal consistency with student samples, as well as strong test-retest reliability, and construct validity ( $\alpha=.92$ in the current study; e.g. Poythress et al., 2010; Ray, Weir, Poythress, \& Rickelm, 2011).

Sexual Assault Transcript. The sexual assault transcript utilized in this study was adapted from an actual court case (R. v. Smith, 2011 ABPC 39). Eligible cases were located through the Canadian Legal Institute database (CanLII; https://www.canlii.org/en/ca/) using sexual assault as search criteria. The selected case was adapted to make guilt determinations more ambiguous, and reflect a "he said, she said" type of case where the only evidence presented is the testimony of the accused. The case involved a scenario in which the accused was charged with sexual assault after a university overnight field trip took place, where the alleged victim claimed that non-con- 
sensual sexual acts occurred and the defendant denied such claims. Apart from these changes, the court transcript was manipulated to include information concerning emotions displayed by the alleged victim and/or defendant. Specifically, emotional details were added to reflect a HIGH emotional display (i.e., "Tears poured from [A.B.]'s eyes while talking about her life after the encounter with Mr. Smith: her head was held low and she talked quietly, appearing to be quite emotional about the subject. The police report indicates [A.B.] had a difficult time recounting what happened to her because she was overcome with emotion. Similarly, her testimony in court was tearful and laden with emotion") or a LOW emotional display (i.e., "In court, [A.B.] appeared unemotional while recounting these details. She spoke in a steady voice and seemed quite poised. Her facial expressions and body posture seemed relaxed and natural") throughout both victim and defendant testimony. In total, four versions of the testimony were created and varied according to defendant emotion (low or high) and victim emotion (low or high).

Jury Outcome Questionnaire (JOQ). This questionnaire was designed for the purposes of the present study, and contained 20 questions in total examining guilt determination (e.g. "Based on the information provided, how would you judge the defendant's guilt?"), truthfulness of defendant and victim testimony (e.g. "Do you think Mr. Smith was telling the truth?”), sentencing (e.g. "If [A.B.] was found to have made a false allegation, what type of sentence do you think she deserves?"), and emotion evoked by defendant and victim testimony (e.g. “To what extent did Mr. Smith’s behavior and testimony make YOU feel emotional?”). Participants were asked to complete each question in relation to the case they read and rate items on a 9-point Likert scale (i.e., from $1=$ not at all to 9 = completely). In addition, some question responses were in forced-choice format where participants indicated responses such as GUILTY/NOT GUILTY or YES/NO concerning questions of criminal culpability and emotionality. Similar questionnaires have been utilized in previous research in order to address dependent measures (e.g., Gunnell \& Ceci, 2010).

Rational Experiential Inventory (REI). The REI (Epstein, Pacini, Denes-Raj, \& Heier, 1996) is a 40-item questionnaire that assessed whether individuals process information in a rational (i.e., analytic, intentional, affect-free; "I prefer complex problems to simple problems") relative to experiential (i.e., intuitive, emotional, automatic; "I believe in trusting my hunches") manner. All items are rated on a 5-point Likert scale from 1 (completely false) to 5 (completely true). This scale has demonstrated reliability (Epstein et al., 1996; Pacini \& Epstein, 1999) and has been utilized in other jury studies evaluating emotion and decision-making bias (e.g., Gunnell \& Ceci, 2010). Further, legal biases have been demonstrated as a function of rational versus experiential processing (e.g., Krauss et al., 2004; Lieberman, 2002), thus relevant to include in the present study.

\subsection{Procedure}

This study was conducted online through the Psychology Research Participant Pool and used Qualtrics survey software to present the information to participants. All participants provided informed consent to participate after reading a description of the study (generally described as a study on personality and jury decision making in sexual assault cases) by clicking "yes" to indicate consent. They were then asked to complete basic demographic information (e.g., age, gender, ethnicity, previous exposure to sexual violence) and the Psychopathic Personality Inventory-Revised (PPI-R; Lilienfeld \& Widows, 2005). The PPI-R was utilized to examine the extent to which participants contained psychopathic traits such as lack of empathy/emotion, manipulativeness, and coldheartedness that may be related to juror biases. These questionnaires were followed by the presentation of one of four sexual assault case transcripts that were ambiguous in terms of what actually happened (i.e., a "he said, she said" case), and varied according to the emotion displayed by the defendant (low/high) and the alleged victim (low/ high). Participants were instructed to read the transcript carefully, and answer subsequent questions in relation to how they felt about the incident as if they were jurors in this trial. Participants then completed the Jury Outcome Questionnaire (JOQ) in response to the transcript they had just read. Next, participants completed the Rational Experiential Inventory (REI; Epstein et al., 1996) to assess the degree of rational versus experiential processing utilized in decision-making. Finally, a manipulation check asked participants to indicate how serious they perceived the sexual assault to be from 1 (not at all serious) to 7 (very serious), as well as the level of emotionality of the defendant and alleged victim (low/high). Participants were then provided a debriefing form and given the researchers' contact information for any follow up questions. The entire study took participants approximately 45 minutes to complete. 


\section{Results}

\subsection{Emotional Content}

In order to examine the extent to which emotional content influenced judicial decision-making, we conducted several types of analyses to address our variables of interest. Using a chi-squared analysis $\left(\chi^{2}\right)$ on guilty/not guilty determinations, we assessed both defendant and claimant emotionality (high/low). These analyses revealed when the defendant was more emotional, the level of guilty/not guilty verdicts was approximately equal, whereas when the defendant was less emotional, participants believed the defendant was guilty more often $\left(\chi^{2}=\right.$ $4.33, p<.05)$. Similarly, there was a trend that approached significance for the alleged victim, where high emotionality was associated with more guilty verdicts relative to low emotionality $\left(\chi^{2}=2.85, p=.09\right)$ (see Figure 1 ). That said, using a 2 (defendant emotionality) $\times 2$ (claimant emotionality) between-subjects univariate analysis of variance (ANOVA) on our sentencing severity variable yielded no differences across emotionality groups for either the defendant or the alleged victim (all $p$ 's $>.05$ ).

We also evaluated several other variables of interest using multivariate analyses of variance (MANOVAs), such as credibility and false allegations. Analysis of assessments of both victim and defendant truthfulness and credibility as a function of emotionality revealed an overall main effect of victim emotionality (Wilks' lambda $\lambda$ $=.93, F(4,363)=6.38, p<.001)$, an overall main effect of defendant emotionality $(\lambda=.93, F(4,363)=3.44, p$ $<.005$ ), but no significant interaction. In particular, the alleged victim was believed to be telling the truth more so when they were highly emotional $(M=6.55, S E=.15)$ relative to less emotional $(M=5.60, S E=.15 ; F(1$, $\left.366)=20.25, p<.001, \eta_{p}^{2}=.05\right)$. Further, ratings of the alleged victim's truthfulness $(F(1,366)=6.37, p<.05$, $\left.\eta_{\mathrm{p}}{ }^{2}=.02\right)$, defendant credibility $\left(F(1,366)=6.61, p<.05, \eta_{p}^{2}=.02\right)$, and defendant truthfulness $(F(1,366)=$ 11.92, $p=.001, \eta_{p}^{2}=.03$ ) all were influenced by the level of emotionality displayed by the defendant Mr. Smith. In particular, when Mr. Smith displayed higher levels of emotion, he was rated as more credible and more likely to be telling the truth (see Figure 2). Finally, the extent to which participants believed the victim was making a false allegation was assessed via a MANOVA utilizing victim and defendant emotionality as the independent factors. This analysis revealed main effects of victim $(\lambda=.98, F(3,332)=2.22, p=.08)$ and defendant $(\lambda=.98, F(3,332)=2.21, p=.09)$ emotionality that approached significance, with no interactive effects. Specifically, this trend resulted from the fact that participants were more likely to believe the alleged victim was making a false allegation when the supposed victim was less emotional $(M=5.11, S E=.18$ v. $M=4.59, S E$ $=.18$ for the high emotion condition; $F(1,334)=4.20, p<.05, \eta_{p}^{2}=.01$ ) or the defendant was more emotional $\left(M=5.13, S E=.18\right.$ v. $M=4.57, S E=.18$ for the low emotion condition; $\left.F(1,334)=5.01, p<.05, \eta_{p}^{2}=.02\right)$.

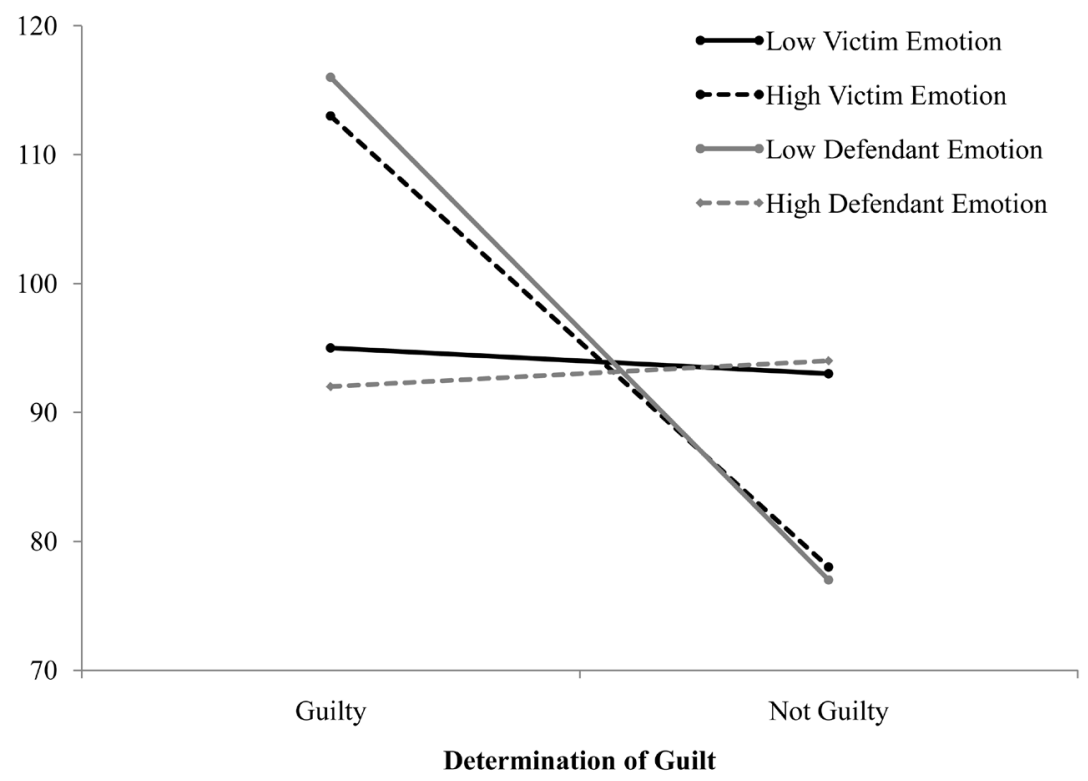

Figure 1. Total number of guilty and not guilty judgments as a function of emotional display (high/low) for both victims and defendants. 


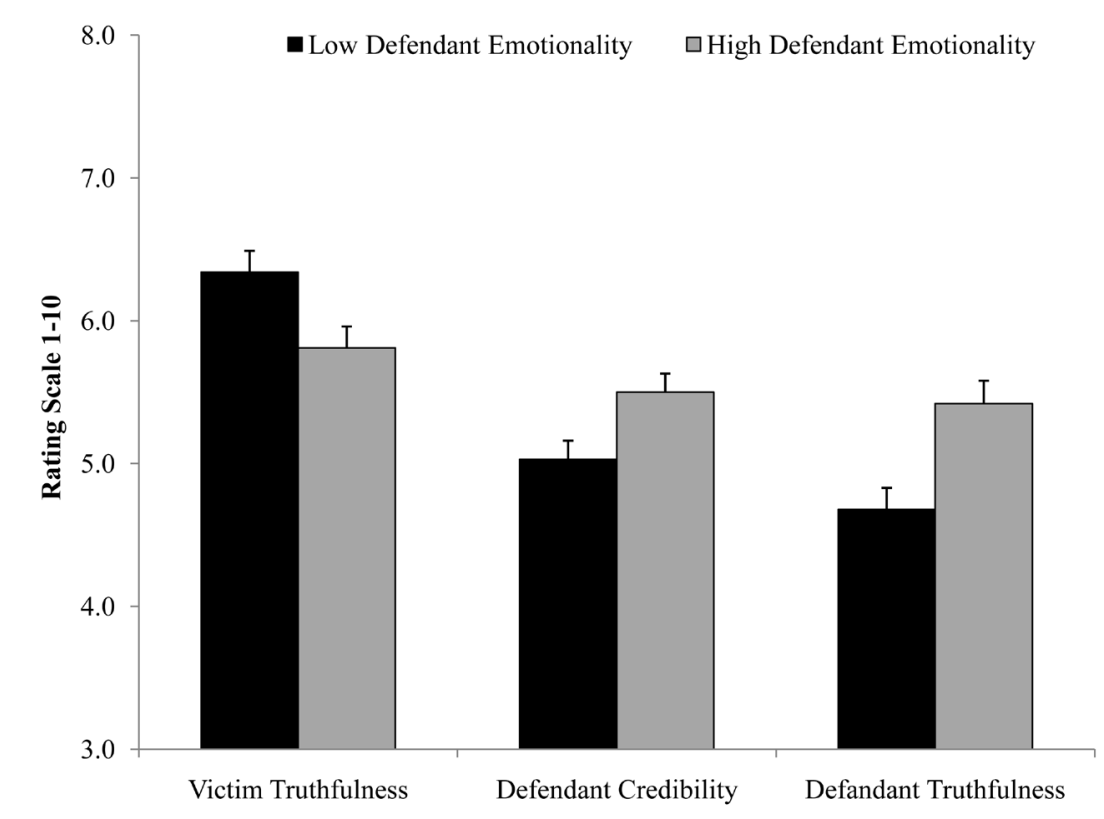

Figure 2. Veracity and credibility ratings as a function of defendant emotionality (low/ high).

\subsection{Psychopathic Traits}

In order to assess whether high relative to low psychopathic traits influenced judicial decision-making as a function of emotion, raw total scores on the PPI-R were tabulated $(M=325.33, S D=24.40)$, transformed into $T$-scores, and then divided according to overall HIGH scores on the PPI-R (i.e., above the $95^{\text {th }}$ percentile norm; $n=170$ ) relative to LOWER scores (i.e., below the $85^{\text {th }}$ percentile norm; $n=87$ ) and excluding participants in the moderate T-score range $(n=126)$. Following this, each of the above analyses was recalculated including psychopathic traits as an additional independent variable.

In regards to sentencing and guilt, levels of psychopathic traits were unrelated to ratings of sentencing severity or guilt determinations, and such ratings did not change across the victim and defendant emotion conditions (all $p$ 's $>.05$ ). Similarly, ratings of truthfulness and credibility on behalf of the alleged victim and the defendant were not influenced by levels of psychopathic traits (all $p$ 's $>.05$ ). Beliefs that the alleged victim may be making a false allegation were influenced by an interaction between level of psychopathic traits and victim emotionality that approached significance $(\lambda=.97, F(3,215)=2.46, p=.06)$. Specifically, univariate analyses revealed that the likelihood of the claim being a false allegation did not change across emotion conditions for the low psychopathic traits group, whereas the group higher in psychopathic traits were more likely to rate the alleged victim as making a false allegation when she was less relative to more emotional $(F(1,217)=2.94, p=.06$ ) (see Figure 3). Further, the low psychopathic traits group were more punitive towards a false allegation (i.e., believing the alleged victim should be formally charged if caught making a false allegation) when the alleged victim was more emotional during their testimony relative to less emotional. In contrast, those in the high psychopathic traits group were less punitive towards a false accuser if they were highly emotional in court $(F(1,217)=4.62, p$ $<.05$ ) (see Figure 4). Due to purported emotional processing deficits associated with psychopathy, we also wanted to examine how individuals low and high in psychopathic traits interpreted the emotional displays of our alleged victim and defendant. Analysis of questions pertaining to both victim and defendant emotional displays did not reveal any differences as a function of psychopathic traits (all $p$ 's $>.05$ ).

\subsection{Processing Style}

In order to assess each participant's processing style, scores on the REI were calculated using Gunnell and Ceci's (2010) method that more appropriately evaluates the extent to which one system overrides the other within a given individual. Firstly, R-processors and E-processors were categorized into four quadrants (i.e. high expe- 


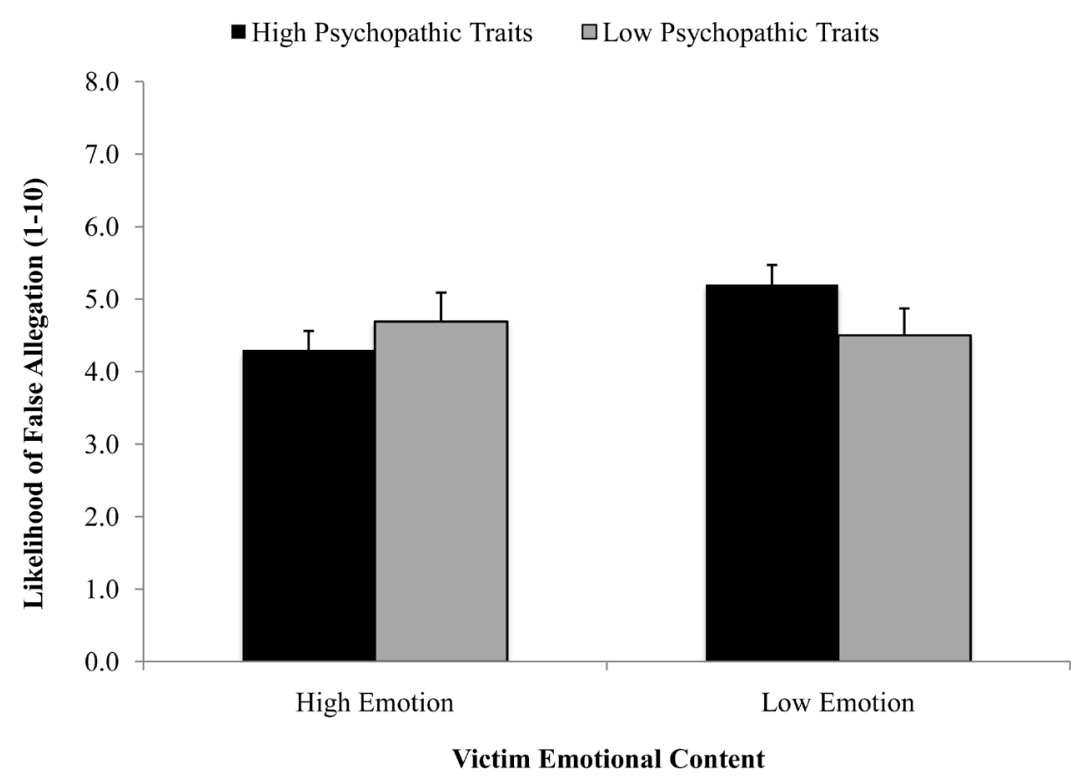

Figure 3. Mean ratings of false allegation likelihood as a function of victim emotion (low/high) and level of psychopathic traits of mock juror (low/high).

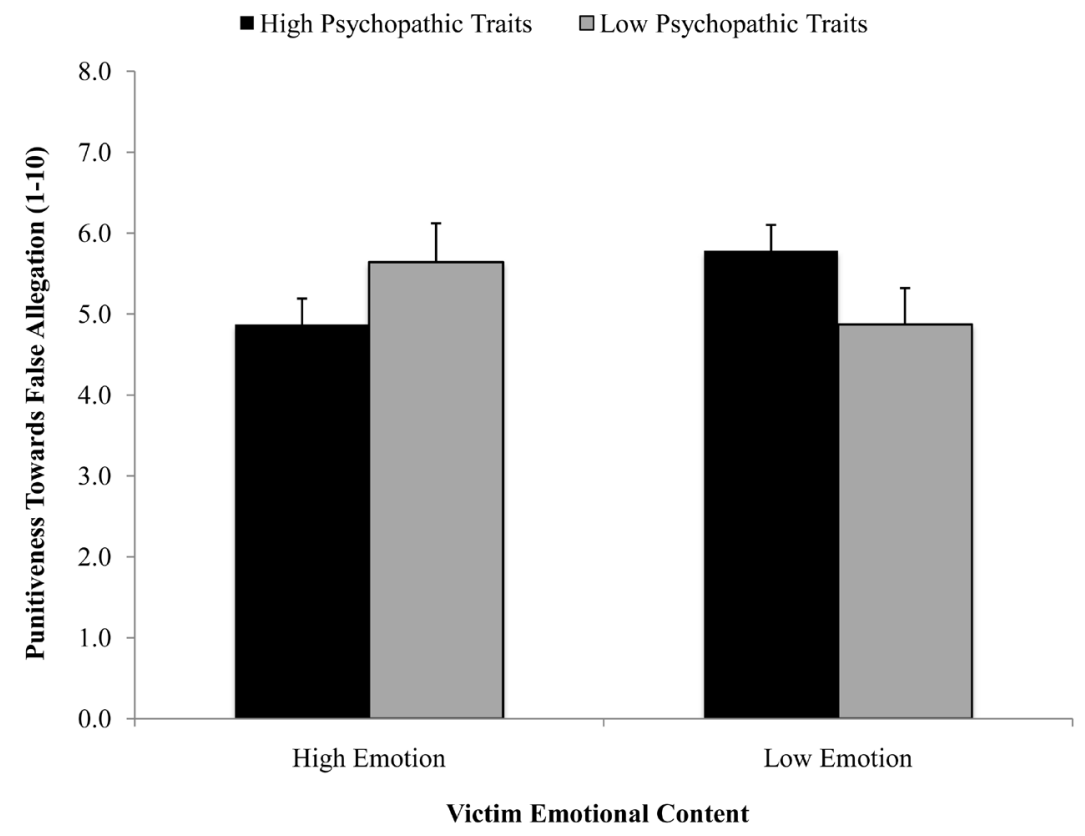

Figure 4. Mean ratings of false allegation punitiveness (i.e., the alleged victim should be formally charged if making a false allegation) as a function of victim emotionality (low/high) and level of psychopathic traits in mock jurors (low/high).

riential/low rational [Q1], high experiential/high rational [Q2], low experiential/low rational [Q3], low experiential/high rational [Q4]). Then, a processing style influence (PSI), where each scale was split at their respective population medians, and then the distance from the median on each scale in relation to the other was calculated for each participant $(\mathrm{PSI}=[$ (median rationality score $)-($ actual rationality score $)]+[$ (actual experientiality score) - (median experientiality score)]; Gunnell \& Ceci, 2010). This was done in order to split individuals falling into Q2 and Q3 as either primarily R-processors or primarily E-processors, where a negative PSI score categorized individuals as primarily R-processors, and a positive PSI score categorized individuals as primarily 
E-processors. Once the final categorizations were made, our sample consisted of 172 R-processors and 187 Eprocessors.

Processing type was found to be related to sentencing severity when the defendant's emotionality was taken into account $(F(1,351)=3.69, p=.05)$. Specifically, E-processors were more punitive towards the defendant when the defendant displayed low levels of emotion relative to high emotionality, whereas R-processors were slightly more punitive when high levels of emotion were being displayed (see Figure 5). Analysis of ratings of truthfulness and credibility as a function of emotionality (victim/defendant) and processing type did not reveal any main effects, but a 3-way interaction approached significance $(\lambda=.97, F(4,355)=2.22, p=.06)$. The data indicates that when the victim is highly emotional, ratings vary across low and high defendant emotionality and processing type. Specifically, it appears as if R-processors are more likely to associate high defendant emotionality with credibility and truthfulness. Processing type was unrelated to any variations in belief that the alleged victim may have been making a false allegation (all $p$ 's $>.05$ ). We also assessed whether interpretations of victim and defendant emotionality varied according to processing type, and found no significant effects (all $p$ 's > .05).

\subsection{Manipulation Check}

As a manipulation check, we had participants rate the level and type of emotionality displayed by both the defendant and the alleged victim. Multivariate analyses of victim emotionality yielded significant differences between the low versus high emotion groups on all emotion rating questions of interest (i.e., how emotional do you think A.B. appeared? $\left.\lambda=.38, F(8,216)=43.32, p<.001, \eta_{p}^{2}=.62\right)$. In particular, ratings of emotionality corresponded directly to whether the alleged victim was displaying low versus high emotionality in their testimony. Similarly, MANOVA analysis of defendant emotionality yielded significant differences between the low versus high emotion groups on all emotion rating questions of interest (i.e., how emotional do you think Mr. Smith appeared? $\left.\lambda=.52, F(8,245)=28.41, p<.001, \eta_{p}^{2}=.48\right)$. Specifically, when the defendant was displaying high levels of emotion, participants rated his emotionality as higher on all emotion questions.

\section{Discussion}

The purpose of the present study was to examine how extralegal factors such as emotion, psychopathic traits, and processing styles influenced juror decision-making in sexual assault cases. Our first set of predictions concerned the level of emotional expression displayed by either the victim, or defendant, or both. Specifically, our

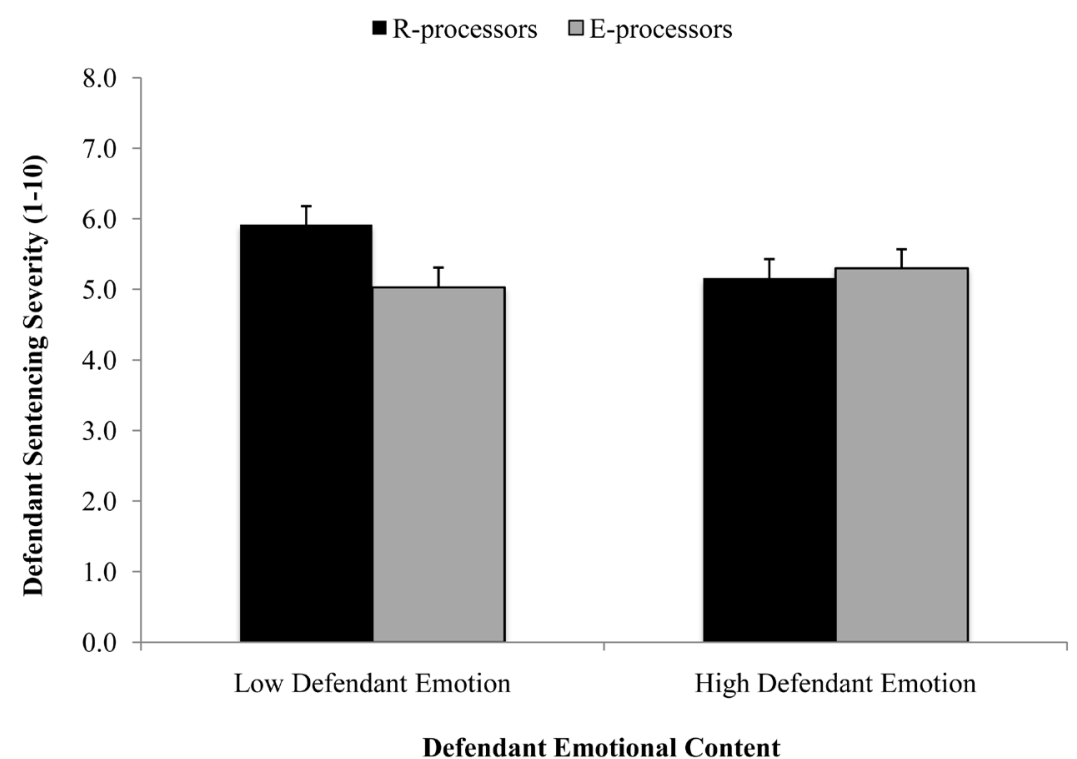

Figure 5. Mean sentencing severity ratings as a function of defendant emotionality (low/high) and juror information processing style (R-processor/E-processor). 
prediction that high victim emotion (or similarly low defendant emotion) would be associated with more punitive decisions towards the defendant was partially supported by our data. In particular, high victim emotion and low defendant emotion (independent of each other) were both associated with a greater proportion of guilty verdicts, and higher truthfulness/credibility ratings on behalf of the alleged victim. On the other hand, when the defendant Mr. Smith displayed more emotion, he was believed to be more credible and more likely telling the truth, although this did not influence guilty verdicts. Sentencing severity was unaffected by the level of emotionality displayed by either victim or defendant and no interactions between these two variables were revealed (i.e., high victim emotion plus low defendant emotion was not associated with the highest ratings of guilt). The data also revealed a trend towards the perception that the victim may be making a false allegation when they are not displaying the expected or appropriate level of "high" emotion, and when the defendant appears to be emotional.

Based on the data above, it appears that mock jurors transfer their belief in who is telling the truth based on who is showing more emotion and whether this fits with expectations (e.g., Ask \& Landström, 2010; Calhoun, Cann, Selby, \& Magee, 1981). In general, research on both true and false allegations has reported that high levels of emotional expression (both in terms of demeanor and content of a claim) are more often associated with a genuine claims of criminal events (e.g., Kaufmann et al., 2003; Peace, Brower, \& Shudra, 2012; Peace, Porter, et al., 2012; Wessel et al., 2006). That said, interactive effects between victim and defendant emotionality may have been constrained due to a form of emotional saturation (see Peace \& Forrester, 2012), where the content of the sexual assault claim (already emotionally arousing in nature) overrides detailed consideration of emotions displayed by both the alleged victim and alleged perpetrator. For example, though Kaufman and colleagues (2003) found that emotion greatly influenced credibility of the witness, guilt determination also varied depending on the content of the rape scenario (i.e., repeated rejection of the sexual advances v. more ambiguous rejection where the alleged victim agrees to some intimate contact but then withdraws). Similar to our results, it also has been found that ratings of crime severity may be more important predictors of sentencing outcomes relative to emotional displays (e.g., Rucker, Polifroni, Tetlock, \& Scott, 2004).

In this case, it may be that the characteristics of the crime played a more important role when making sentencing decisions rather than the emotional displays of both victim and defendant, or that jurors are only able to attend to what is believed to be the predominant emotional display (even though both parties may be expressing emotion). In particular, the authors believe that more attention is paid to victim emotionality in general relative to the behaviour of the defendant in such cases (e.g., Ellison \& Munro, 2009). In fact, evaluation of our manipulation check data indicates this may be the case, such that victims in the high emotional condition were rated as "more emotional" than defendants in the high emotional condition. Therefore, it appears likely that we have an inherent bias (consistent with expectations) that victims are to be emotional whereas the behaviour of perpetrators is less critical in case outcomes. Further, if these emotional responses are deemed "appropriate" in congruence with the level of severity of the crime, mock jurors are more likely to assign higher punitiveness ratings to alleged perpetrators (Rose, Nadler, \& Clark, 2006). In our study, such polarized ratings may have been limited by the ambiguity of the sexual assault case presented, and the moderate level of severity of the crime (i.e., there was no extensive physical violence associated with the assault).

That said, defendant emotionality also yielded significant outcomes relative to guilt determinations and truthfulness in line with affect control theory (Tsoudis, 2002). Specifically, jurors may attend to aspects of the defendant's demeanor and emotionality given that the outcomes of a trial effect the alleged perpetrator more strongly than the alleged victim. The extent to which the defendant controls their affect (or fails to do so in cases of angry outbursts) can then be associated with more guilt determinations and negative sentencing outcomes (e.g., Tsoudis \& Smith-Lovin, 1998; Tsoudis, 2002). Finally, it may be the timing of emotional information displayed (especially by defendants) that influences sentencing outcomes more so than simply the presence of emotionality. For example, Heath et al. (2004) reported that greater emotional displays prior to guilt determinations led to less punitive sentencing. However, extant research suggests that a defendant's emotional display after a guilty verdict may be of greater diagnostic value in sentencing outcomes. Specifically, emotional displays that are interpreted as indicative of remorse for the action (when defendants were previously found guilty) lead to less severe punishments (e.g., Eisenberg, Garvey, \& Wells, 1997; Everett \& Nienstedt, 1999; Robinson, Smith-Lovin, \& Tsoudis, 1994). Given that only one experiment has found sentencing variance in outcomes due to emotional displays of defendants prior to guilt determinations, it may be that emotional cues of a defendant are used to infer overall guilt determinations (i.e. either guilty or not guilty, and additionally veracity and credibility judgments), but do not influence sentencing outcomes. Future research should address expectations of victim and 
defendant emotionality, crime severity and type, as well as the presentation of emotional displays and content in order to better understand how emotion influences jury decision-making.

The second purpose of this study was to examine the role of psychopathic traits in emotional case processing. Our prediction that individuals high in psychopathic traits would be less likely to use emotional information when making sentencing, credibility, and guilt determinations relative to individuals low on psychopathic traits (i.e., ratings would not change as a function of emotion) was not supported. In fact, levels of psychopathic traits were unrelated to changes in any of these variables and were not dependent on victim or defendant emotionality. As mentioned previously, it may be that psychopathy is more related to decisions involving either affective (hot) empathy or cognitive (cold) empathy (e.g., Domes et al., 2013; Dutton, 2012; Mullins-Nelson et al., 2006). In the present case, judicial decisions concerned the outcomes of other persons with little self-relevance to the mock juror, and therefore may only have activated pathways associated with cognitive empathy for all participants. However, if cases could be presented that varied according to the level of personal versus impersonal empathy elicited, this is where differences in decisions made by psychopaths versus non-psychopaths may be evidenced (i.e., Cima, Tonnaer, \& Hauser, 2010). In addition, detection of between-group differences in our sample also may have been constrained by their scores on our measure of psychopathic traits overall. In particular, the current sample scored quite high on psychopathic traits in general, leading to our "low psychopathic trait" individuals to be classified as the $85^{\text {th }}$ percentile or below (with the average low score falling at the $73^{\text {rd }}$ percentile; $M=294.63, S D=9.30$ ) relative to the average "high" score at the $98^{\text {th }}$ percentile for community samples $(M=346.95, S D=16.41)$. While the "low" group scored lower than the "high" group, this group likely does not reflect actual low scores on psychopathic traits given that the vast majority of our sample scored in the $85^{\text {th }}$ percentile or higher $(n=297)$. For this reason, it may be more appropriate to classify our entire sample as being relatively high in psychopathic traits. This interpretation is supported by the finding that empathic responses to the defendant and alleged victim emotionality did not differ across our low and high psychopathic groups (as measured by items on our questionnaire such as "To what extend did Mr. Smith's/A.B.'s behaviour and testimony make YOU feel: emotional, angry, sad”, etc. as rated on a 10-point Likert scale). Not only is a lack of empathy a defining characteristic of psychopathy (Benning et al., 2003), but also the characteristic of most interest to the current study. Another sample with more appropriate low scores (i.e., below the $50^{\text {th }}$ percentile as indicated by the PPI-R manual's community/college sample total scores; Lilienfeld \& Widows, 2005) would be required in order to adequately evaluate the effect of psychopathic traits on processing of emotional information in judicial decisions. In fact, the only outcomes that approached significance in relation to psychopathic traits concerned whether participants believed the alleged victim was making a false allegation or not. Specifically, individuals high in psychopathic traits were more likely to rate the alleged victim as making a false allegation when victim emotional content was low, relative to high, as whereas individuals low in psychopathic traits did not differ in their beliefs concerning false allegations. This may be related to recent research that has demonstrated a distinct advantage that psychopaths appear to have in identifying and inferring emotional content and vulnerability (through nonverbal behaviour and facial expressions) in victim populations (e.g., Book, Costello, \& Camilleri, 2013; Book, Quinsey, \& Langford, 2007; Wilson, Demetrioff, \& Porter, 2008). In this sense, individuals high in psychopathic traits may have been more likely to interpret the victim's display of emotionality as non-genuine thus increasing ratings of false allegations. Further, such individuals also may have a tendency to rate victims and others as "weak" or more negatively overall (Black, Woodworth, \& Porter, 2014), and subsequently less believable, potentially leading to ratings of disbelief in the current study. In fact, our data indicated that it was only when the victim displayed a high level of emotion that jurors high in psychopathic traits responded with less punitiveness towards charging the victim (i.e., for potentially making a false allegation). In contrast, individuals lower in psychopathic traits were more punitive towards the alleged victim when the victim displayed high levels of emotion. In this instance, perhaps we are seeing a difference in empathic response where individuals low in psychopathic traits may have a stronger emotional reaction (i.e., disgust or anger) to an alleged victim they believe to be making a false allegation relative to individuals high in psychopathic traits. More research is needed to elucidate the relationship between psychopathic traits, emotional responding, and empathy in these types of decision-making contexts.

The final purpose of this study was to investigate how different processing styles (rational versus experiential) were related to decision-making, emotional interpretations, and psychopathic traits. We predicted that E-processors would be more influenced by the emotion expressed by the victim and/or defendant relative to R-processors, whose ratings should remain unaffected by emotion. These predictions were partially supported. Our 
analysis revealed that individuals classified as E-processors gave more severe sentences to defendants when defendant emotional content was low. This finding is in line with past research by Gunnell and Ceci (2010) that found E-processors to be more severe in their sentencing decisions and more heavily influenced by extralegal information relative to R-processors. That said, several interesting and unexpected patterns also were revealed in this study. R-processors tended to judge the defendant more harshly when they displayed high levels of emotion relative to low emotion (overall), opposite to the above finding. It is possible that individuals who put more weight on the evidence and logistics of a case are more likely to interpret emotion on behalf of the defendant as a ruse or manipulative tactic for leniency (i.e., Tsoukas \& Smith, 1998), and are more punitive as a result. Similarly, R-processors may be more likely to perceive the evidence in a case differently (i.e., less ambiguous), also influencing their judgments. For example, strong displays of defendant emotionality have led to less guilty verdicts and punitiveness when evidence against the defendant is weak (Heath et al., 2004). However in our study, the case was intentionally ambiguous, leaving room for individual juror interpretations of evidentiary strength. Related to this interpretation was our finding that when the alleged victim was highly emotional as well as the defendant, R-processors were more likely to associate greater credibility and truthfulness to the defendant rather than the victim. As stated previously, the context of a situation can influence the extent to which individuals employ a rational or experiential processing mode (Epstein et al., 1996). In our study, the information provided to participants was highly ambiguous, in that there was no information available that could reliably detail whether the sexual encounter was truly sexual assault or whether it was consensual. Given this finding, R-processors may have turned to the emotional content of both the defendant and victim as cues to veracity, whereas E-processors responded more empathically to the victim emotionality and thus focused more on this in their decisionmaking. Unfortunately we did not ask participants to indicate the extent to which they felt the evidence supported the alleged victim or defendant's version of events, or which they focused on or weighted more heavily, but this would be advised in future studies to clarify this issue.

\section{Conclusion}

Collectively, this and previous studies have demonstrated that emotionality (and the processing of such emotion) can influence trial outcomes. Therefore it is important to examine the emotion expressed by victims and defendants, as well as the level of emotional responsiveness and personality of jurors in courtroom contexts. We have shown that guilt determinations, interpretations of truthfulness and credibility, and ratings of false allegations all may be related to emotional displays and content. While much research remains to be conducted, this study provides a glimpse into some influentially extralegal factors on case outcomes, and identified future areas of investigation.

\section{References}

Ask, K., \& Landström, S. (2010). Why Emotions Matter: Expectancy Violation and Affective Response Mediate the Emotional Victim Effect. Law and Human Behavior, 34, 392-401. http://dx.doi.org/10.1007/s10979-009-9208-6

Batson, C. D., Klein, T. R., Highberger, L., \& Shaw, L. L. (1995). Immorality from Empathy-Induced Altruism: When Compassion and Justice Conflict. Journal of Personality and Social Psychology, 68, 1042-1054. http://dx.doi.org/10.1037/0022-3514.68.6.1042

Benning, S. D., Patrick, C. J., Hicks, B. M., Blonigen, D. M., \& Krueger, R. F. (2003). Factor Structure of the Psychopathic Personality Inventory: Validity and Implications for Clinical Assessment. Psychological Assessment, 15, 340-350. http://dx.doi.org/10.1037/1040-3590.15.3.340

Black, P. J., Woodworth, M., \& Porter, S. (2014). The Big Bad Wolf? The Relation between the Dark Triad and the Interpersonal Assessment of Vulnerability. Personality and Individual Differences, 67, 52-56. http://dx.doi.org/10.1016/j.paid.2013.10.026

Blais, J., \& Forth, A. E. (2014). Potential Labeling Effects: Influence of Psychopathy Diagnosis, Defendant Age, and Defendant Gender on Mock Jurors’ Decisions. Psychology, Crime \& Law, 20, 116-134. http://dx.doi.org/10.1080/1068316X.2012.749473

Block, S. D., Greenberg, S. N., \& Goodman, G. S. (2009). Remembrance of Eyewitness Testimony: Effects of Emotional Content, Self-Relevance, and Emotional Tone. Journal of Applied Social Psychology, 39, 2859-2878.

http://dx.doi.org/10.1111/j.1559-1816.2009.00553.x

Bollingmo, G. C., Wessel, E. O., Eilertsen, D. E., \& Magnussen, S. (2008). Credibility of the Emotional Witness: A Study of 
Ratings by Police Investigators. Psychology, Crime \& Law, 14, 29-40. http://dx.doi.org/10.1080/10683160701368412

Book, A., Costello, K., \& Camilleri, J. A. (2013). Psychopathy and Victim Selection: The Use of Gait as a Cue to Vulnerability. Journal of Interpersonal Violence, 28, 2368-2383. http://dx.doi.org/10.1177/0886260512475315

Book, A. S., Quinsey, V. L., \& Langford, D. (2007). Psychopathy and the Perception of Affect and Vulnerability. Criminal Justice and Behavior, 34, 531-544. http://dx.doi.org/10.1177/0093854806293554

Burgoon, J. K. (1993). Interpersonal Expectations, Expectancy Violations, and Emotional Communication. Journal of Language and Social Psychology, 12, 30-48. http://dx.doi.org/10.1177/0261927X93121003

Calhoun, L. G., Cann, A., Selby, J. W., \& Magee, D. L. (1981). Victim Emotional Response: Effects on Social Reaction to Victims of Rape. British Journal of Social Psychology, 20, 17-21. http://dx.doi.org/10.1111/j.2044-8309.1981.tb00468.x

Cima, M., Tonnaer, F., \& Hauser, M. D. (2010). Psychopaths Know Right from Wrong but Don’t Care. Social Cognitive and Affective Neuroscience, 5, 59-67. http://dx.doi.org/10.1093/scan/nsp051

Domes, G., Hollerbach, P., Vohs, K., Mokros, A., \& Habermeyer, E. (2013). Emotional Empathy and Psychopathy in Offenders: An Experimental Study. Journal of Personality Disorders, 27, 67-84. http://dx.doi.org/10.1521/pedi.2013.27.1.67

Du Mont, J., Miller, K. L., \& Myhr, T. L. (2003). The Role of "Real Rape” and "Real Victim” Stereotypes in the Police Reporting Practices of Sexually Assaulted Women. Violence against Women, 9, 466-486. http://dx.doi.org/10.1177/1077801202250960

Dutton, K. (2012). The Wisdom of Psychopaths: What Saints, Spies, and Serial Killers Can Teach Us about Success. Toronto, ON: Anchor Canada.

Edens, J. F., Colwell, L. H., Desforges, D. M., \& Fernandez, K. (2005). The Impact of Mental Health Evidence on Support for Capital Punishment: Are Defendants Labeled Psychopathic Considered More Deserving of Death? Behavioral Sciences and the Law, 23, 603-625. http://dx.doi.org/10.1002/bsl.660

Edens, J. F., Petrila, J., \& Buffington-Vollum, J. K. (2001). Psychopathy and the Death Penalty: Can the Psychopathy Checklist-Revised Identify Offenders Who Represent “a Continuing Threat to Society?” Journal of Psychiatry \& Law, 29, 433-481.

Eisenberg, T., Garvey, S. P., \& Wells, M. T. (1997). But Was He Sorry? The Role of Remorse in Capital Sentencing. Cornell Law Review, 83, 1599-1637.

Ellison, L., \& Munro, V. E. (2009). Reacting to Rape: Exploring Mock Jurors’ Assessments of Complainant Credibility. British Journal of Criminology, 49, 202-219. http://dx.doi.org/10.1093/bjc/azn077

Epstein, S. (2003). Cognitive-Experiential Self-Theory of Personality. In T. Millon, \& M. J. Lerner (Eds.), Handbook of Psychology: Volume 5: Personality and Social Psychology (pp. 159-184). Hoboken, NJ: John Wiley \& Sons.

Epstein, S., Pacini, R., Denes-Raj, V., \& Heier, H. (1996). Individual Differences in Intuitive-Experiential and AnalyticalRational Thinking Styles. Journal of Personality and Social Psychology, 71, 390-405.

http://dx.doi.org/10.1037/0022-3514.71.2.390

Everett, R. S., \& Nienstedt, B. C. (1999). Race, Remorse, and Sentence Reduction: Is Saying You're Sorry Enough? Justice Quarterly, 16, 99-122. http://dx.doi.org/10.1080/07418829900094071

Gunnell, J. J., \& Ceci, S. J. (2010). When Emotionality Trumps Reason: A Study of Individual Processing Style and Juror Bias. Behavioral Sciences \& the Law, 28, 850-877. http://dx.doi.org/10.1002/bsl.939

Hackett, L., Day, A., \& Mohr, P. (2008). Expectancy Violation and Perceptions of Rape Victim Credibility. Legal and Criminological Psychology, 13, 323-334. http://dx.doi.org/10.1348/135532507X228458

Hare, R. D. (1996). Psychopathy: A Clinical Construct Whose Time Has Come. Criminal Justice and Behavior, 23, 25-54. http://dx.doi.org/10.1177/0093854896023001004

Heath, W. P., Grannemann, B. D., \& Peacock, M. A. (2004). How the Defendant’s Emotion Level Affects Mock Jurors’ Decisions When Presentation Mode and Evidence Strength Are Varied. Journal of Applied Social Psychology, 34, 624-664. http://dx.doi.org/10.1111/j.1559-1816.2004.tb02563.x

Holstein, J. A. (1985). Jurors’ Interpretations and Jury Decision Making. Law and Human Behavior, 9, 83-100. http://dx.doi.org/10.1007/BF01044291

Johnson, J. D., Simmons, C. H., Jordav, A., Maclean, L., Taddei, J., Thomas, D., Dovidio, J. F., \& Reed, W. (2002). Rodney King and OJ Revisited: The Impact of Race and Defendant Empathy Induction on Judicial Decisions. Journal of Applied Social Psychology, 32, 1208-1223. http://dx.doi.org/10.1111/j.1559-1816.2002.tb01432.x

Kaufmann, G., Drevland, G. C. B., Wessel, E., Overskeid, G., \& Magnussen, S. (2003). The Importance of Being Earnest: Displayed Emotions and Witness Credibility. Applied Cognitive Psychology, 17, 21-34. http://dx.doi.org/10.1002/acp.842

Klippenstine, M. A., \& Schuller, R. (2012). Perceptions of Sexual Assault: Expectancies Regarding the Emotional Response of a Rape Victim over Time. Psychology, Crime, and Law, 18, 79-94. http://dx.doi.org/10.1080/1068316X.2011.589389 
Krauss, D. A., Lieberman, J. D., \& Olson, J. (2004). The Effects of Rational and Experiential Information Processing of Expert Testimony in Death Penalty Cases. Behavioral Sciences \& the Law, 22, 801-822. http://dx.doi.org/10.1002/bsl.621

Lieberman, J. D. (2002). Head over the Heart or Heart over the Head? Cognitive Experiential Self-Theory and Extralegal Heuristics in Juror Decision Making. Journal of Applied Social Psychology, 32, 2526-2553. http://dx.doi.org/10.1111/j.1559-1816.2002.tb02755.x

Lieberman, J. D., Krauss, D. A., Kyger, M., \& Lehoux, M. (2007). Determining Dangerousness in Sexually Violent Predator Evaluations: Cognitive-Experiential Self-Theory and Juror Judgments of Expert Testimony. Behavioral Sciences \& the Law, 25, 507-526. http://dx.doi.org/10.1002/bsl.771

Lilienfeld, S. O., \& Widows, M. R. (2005). Psychopathic Personality Inventory-Revised: Professional Manual. Lutz, FL: Psychological Assessment Resources Inc.

Mazzella, R., \& Feingold, A. (1994). The Effects of Physical Attractiveness, Race, Socioeconomic Status, and Gender of Defendants and Victims on Judgments of Mock Jurors: A Meta-Analysis. Journal of Applied Social Psychology, 24, 13151338. http://dx.doi.org/10.1111/j.1559-1816.1994.tb01552.x

Mullins-Nelson, J. L., Salekin, R. T., \& Leistico, A. R. (2006). Psychopathy, Empathy, and Perspective-Taking Ability in a Community Sample: Implications for the Successful Psychopathy Concept. International Journal of Forensic Mental Health, 5, 133-149. http://dx.doi.org/10.1080/14999013.2006.10471238

Murrie, D. C., Boccaccini, M. T., \& McCoy, W. (2007). Diagnostic Labeling in Juvenile Court: How Do Descriptions of Psychopathy and Conduct Disorder Influence Judges? Journal of Clinical Child and Adolescent Psychology, 36, $228-241$. http://dx.doi.org/10.1080/15374410701279602

Pacini, R., \& Epstein, S. (1999). The Relation of Rational and Experiential Information Processing Styles to Personality, Basic Beliefs, and the Ratio-Bias Phenomenon. Journal of Personality and Social Psychology, 76, 972-987. http://dx.doi.org/10.1037/0022-3514.76.6.972

Peace, K. A., Brower, K. L., \& Shudra, R. D. (2012). Fact or Fiction? Discriminating True and False Allegations of Victimization. In A. N. Hutcherson (Ed.), Psychology of Victimization (pp. 1-79). Hauppauge, NY: Nova Science Publishers.

Peace, K. A., \& Forrester, D. (2012). Gender, Emotionality, and Victim Impact Statements. Journal of Criminal Psychology, 2, 107-120. http://dx.doi.org/10.1108/20093821211264423

Peace, K. A., Porter, S., \& Almon, D. F. (2012). Sidetracked by Emotion: Observers’ Ability to Discriminate Genuine and Fabricated Sexual Assault Allegations. Legal and Criminological Psychology, 17, 322-335. http://dx.doi.org/10.1111/j.2044-8333.2011.02013.x

Peace, K. A., \& Sinclair, S. M. (2012). Cold-Blooded Lie Catchers? An Investigation of Psychopathy, Emotional Processing, and Deception Detection. Legal and Criminological Psychology, 17, 177-191. http://dx.doi.org/10.1348/135532510X524789

Poythress, N. G., Lilienfeld, S. O., Skeem, J. L., Douglas, K. S., Edens, J. F., Epstein, M., \& Patrick, C. J. (2010). Using the PCL-R to Help Estimate the Validity of Two Self-Report Measures of Psychopathy with Offenders. Assessment, 17, 206219. http://dx.doi.org/10.1177/1073191109351715

Ray, J. V., Weir, J. W., Poythress, N. G., \& Rickelm, A. (2011). Correspondence between the Psychopathic Personality Inventory and the Psychopathic Personality Inventory Revised: A Look at Self-Reported Personality Traits. Criminal Justice and Behavior, 38, 375-385. http://dx.doi.org/10.1177/0093854811398178

Robinson, D. T., Smith-Lovin, L., \& Tsoudis, O. (1994). Heinous Crime or Unfortunate Accident? The Effects of Remorse on Responses to Mock Criminal Confessions. Social Forces, 73, 175-190. http://dx.doi.org/10.1093/sf/73.1.175

Rose, M. R., Nadler, J., \& Clark, J. (2006). Appropriately Upset? Emotion Norms and Perceptions of Crime Victims. Law and Human Behavior, 30, 203-219. http://dx.doi.org/10.1007/s10979-006-9030-3

Rucker, D. D., Polifroni, M., Tetlock, P. E., \& Scott, A. L. (2004). On the Assignment of Punishment: The Impact of General-Societal Threat and the Moderating Role of Severity. Personality and Social Psychology Bulletin, 30, 673-684. http://dx.doi.org/10.1177/0146167203262849

R. v. Smith, 2011 ABPC 39 (CanLII). http://canlii.ca/t/2fn51

Salekin, R. T., Ogloff, J. R., McFarland, C., \& Rogers, R. (1995). Influencing Jurors’ Perceptions of Guilt: Expression of Emotionality during Testimony. Behavioral Sciences \& the Law, 13, 293-305. http://dx.doi.org/10.1002/bsl.2370130208

Simon, R. J. (1963). Mental Patients as Jurors. Human Organization, 22, 276-282.

Tsoudis, O. (2002). The Influence of Empathy in Mock Jury Criminal Cases: Adding to the Affect Control Model. Western Criminology Review, 4, 55-67.

Tsoudis, O., \& Smith-Lovin, L. (1998). How Bad Was It? The Effects of Victim and Perpetrator Emotion on Responses to Criminal Court Vignettes. Social Forces, 77, 695-722. http://dx.doi.org/10.1093/sf/77.2.695 
Wessel, E., Drevland, G. C. B., Eilertsen, D. E., \& Magnussen, S. (2006). Credibility of the Emotional Witness: A Study of Ratings by Court Judges. Law and Human Behavior, 30, 221-230. http://dx.doi.org/10.1007/s10979-006-9024-1

Wilson, K., Demetrioff, S., \& Porter, S. (2008). A Pawn by Any Other Name? Social Information Processing as a Function of Psychopathic Traits. Journal of Research in Personality, 42, 1651-1656. http://dx.doi.org/10.1016/j.jrp.2008.07.006

Winkel, F. W., \& Koppelaar, L. (1991). Rape Victims' Style of Self-Presentation and Secondary Victimization by the Environment: An Experiment. Journal of Interpersonal Violence, 6, 29-40. http://dx.doi.org/10.1177/088626091006001003 
Scientific Research Publishing (SCIRP) is one of the largest Open Access journal publishers. It is currently publishing more than 200 open access, online, peer-reviewed journals covering a wide range of academic disciplines. SCIRP serves the worldwide academic communities and contributes to the progress and application of science with its publication.

Other selected journals from SCIRP are listed as below. Submit your manuscript to us via either submit@scirp.org or Online Submission Portal.
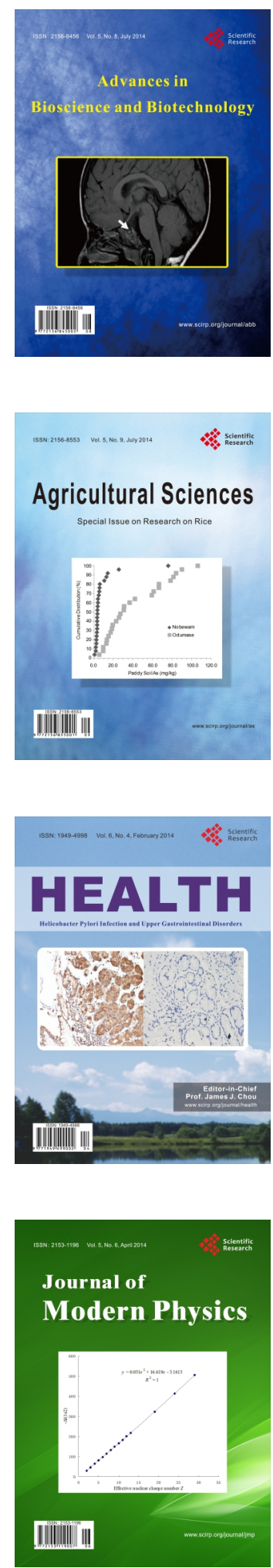
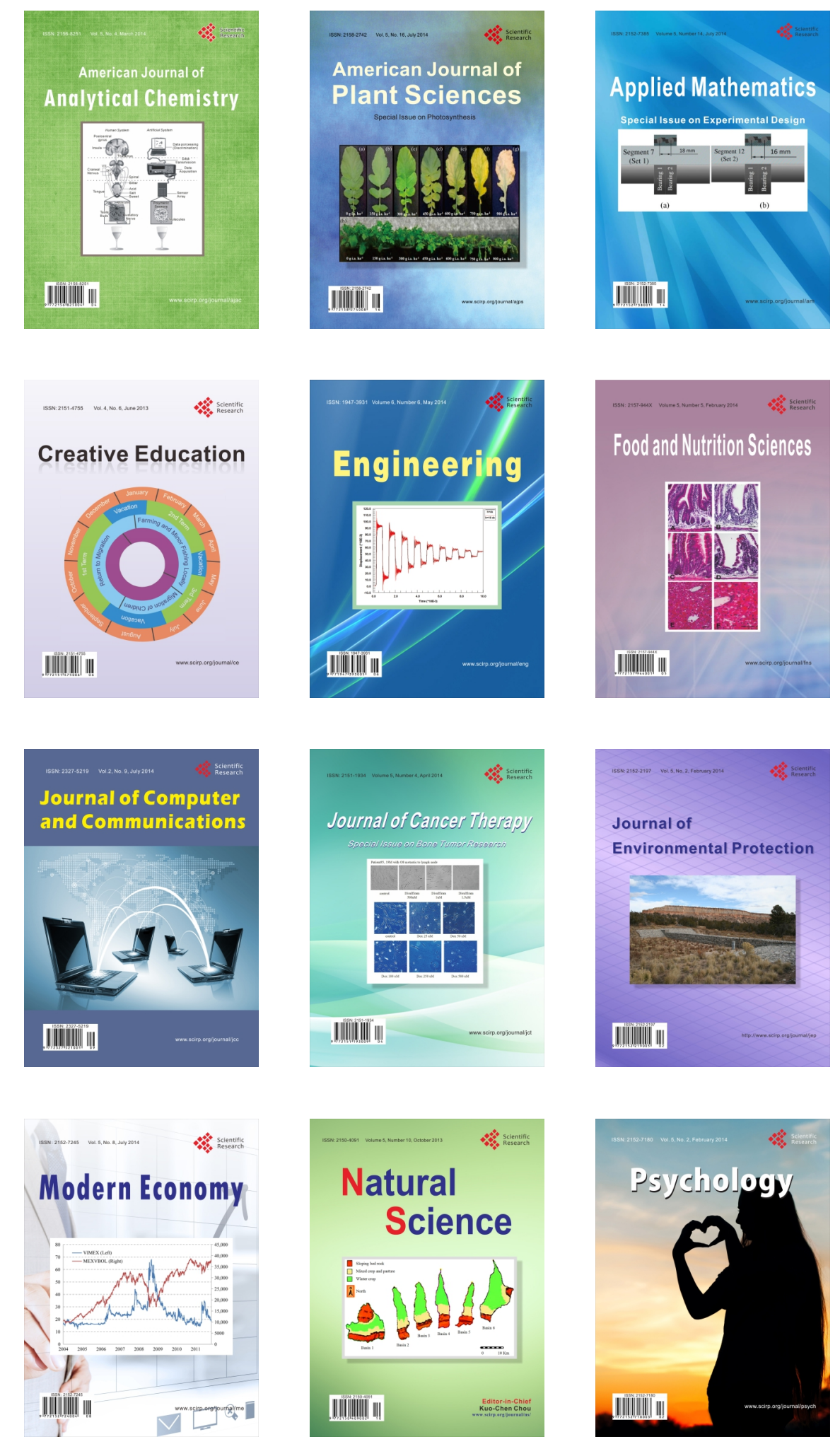